\title{
Pattern of Injuries in Occupants of Vehicular Accidents - An Autopsy Study
}

\author{
Dipu Mohan ${ }^{1}$, Thankamma P. George ${ }^{2}$, Sasikala K. ${ }^{3}$, Sujisha S.S. ${ }^{4}$
}

\begin{abstract}
${ }^{1}$ Department of Forensic Medicine, General Hospital, Thiruvananthapuram, Kerala, India. ${ }^{2}$ Department of Forensic Medicine, Government Medical College, Thiruvananthapuram, Kerala, India. ${ }^{3}$ Department of Forensic Medicine, Government Medical College, Thiruvananthapuram, Kerala, India. ${ }^{4}$ Department of

Forensic Medicine, Government Medical College, Thiruvananthapuram, Kerala, India.
\end{abstract}

\section{ABSTRACT}

\section{BACKGROUND}

Road traffic accidents are one of the leading causes of death worldwide. By the year 2020 , it is projected that road traffic accidents will become the second leading cause of death worldwide next to ischemic heart disease. Vehicular occupant is one who is on a vehicle. The pattern of injuries and the cause of death depends on the type of occupant.

\section{METHODS}

This study was carried out on three hundred and fifty road traffic accident cases brought for autopsy at the mortuary, Government Medical College Hospital, Thiruvananthapuram, during the period March 2012 - March 2013.

\section{RESULTS}

Of a total of 350 cases, motorcycles accounted for $75.8 \%$, followed car (11.1\%), auto rickshaw $(7.4 \%)$, cycle $(2.6 \%)$, bus $(2 \%)$ and lorry $(1.1 \%)$. Among the 350 cases, 346 of them $(98.5 \%)$ had head injury. Upper and lower limbs sustained most of the external injuries in all cases.

\section{CONCLUSIONS}

Strict laws should be brought against drunken driving, rash driving, and driving without helmets, seat belts, and using mobile phones while driving. Violation of traffic rules must be viewed seriously.

\section{KEY WORDS}

Accidents, Injuries, Occupants
Corresponding Author: Dr. Thankamma P. George, TC 2/2068, White House, Jeevan Nagar, Pattom P.O., Thiruvananthapuram-695004, Kerala, India.

E-mail: geetharoy11@gmail.com

DOI: $10.14260 / \mathrm{jemds} / 2020 / 417$

Financial or Other Competing Interests: None.

How to Cite This Article:

Mohan D, George TP, Sasikala K, et al. Pattern of injuries in occupants of vehicular accidents- an autopsy study. J. Evolution Med. Dent. Sci. 2020;9(26): 1916-1921, DOI: 10.14260/jemds/2020/417

Submission 09-03-2020, Peer Review 27-05-2020,

Acceptance 05-06-2020, Published 29-06-2020. 


\section{BACKGROUND}

Road traffic accidents represent a major epidemic of noncommunicable disease in the present century. WHO defines accident as 'an unpremeditated event resulting in recognizable damage' or in other words 'occurrence in sequence of events which usually produces unintended injury, death or property damage'. By the year 2020, it is projected that road traffic accidents will become the second leading cause of death worldwide next to ischemic heart disease. By the term occupant we mean it to be anyone who is holding a position or place.

Motorcycle occupants can be either rider (one who rides the vehicle) or a pillion rider (one who occupies the back seat). In case of a three-wheeler; like auto rickshaw; occupant can be a driver or a back-seat occupant (passenger). Whereas in case of four-wheeler; the occupant can be of three types; namely the driver, front seat occupant or a back-seat occupant.

The above categorization is done due to the evidences that the pattern of injury in each group is of specific nature and varies with other kind of occupants. It has been read from the literatures that the pattern of injuries and the cause of death in each type will be hallmarked to each type of occupants.

In this era numerous protective gadgets are worn by the occupants of each kinds of vehicles to minimize the impact of crashes on their body. Seat belts in case of four wheelers and crash helmets for two wheelers are the best examples. They not only protect the occupants but also give a good survival rate if caught in accidents. New generation vehicles too have in them so many protective elements like airbags anti-locking brake system (ABS) to ensure safety to their occupants.

Hence this study is of immense importance and is a study of this time due to the following reasons.

This study will help to find out the a) Socio-demographic data of the subjects involved. This will give an indirect assessment of the economic loss, b) the nature and pattern of injuries in two, three and four wheeler occupants, c) the distribution of injuries d) the relation of distribution of injuries and the nature of incident and e) to plan measures to reduce the incidence of mortality and morbidity.

The outcome of vehicular collision depends on the safety gadgets like seat belts, oblique impact, skidding, impact with a deformable structure etc. Whereas the factors determining the pattern of injuries in a vehicle occupant in road traffic accidents depends on various forces to which they are subjected and the direction from which they comes. ${ }^{1}$

In a vehicular crash there are three types of collisions occurring. The first one is the vehicle collision. The second collision is the human collision. The third collision is the internal collision. In this type the internal organs of the occupant will move towards the point of impact and hits the other organs, bones and the skull. Even though the body seems to appear normal the internal injuries will be present in gross severity. Impact on the head will lead on to closed head injuries when the brain decorates as it hits on the skull or gets torn by the fractured skull bones. All these injuries may be hard to see but are truly fatal. ${ }^{2}$

\section{METHODS}

This descriptive study was conducted on all cases of road traffic accidents who were occupants of any vehicle brought for autopsy at State medico legal institute during the study period. The study was conducted after getting institutional ethics committee clearance.

The study was conducted from 1st March 2012 to 31st March 2013. Study sample was three hundred and fifty road traffic accident cases who were occupants of vehicles brought for autopsy at Mortuary, Government Medical College Hospital, Thiruvananthapuram, during the study period. General information regarding demographic profile, socioeconomic status etc. of each case were collected from relatives and informed consent taken from them. During autopsy the internal organs were examined for any injuries and when present, details like nature of the injury and the location was noted. Relationship between the presence of external injuries and their correlation to internal injuries were specifically looked into.

\section{Statistical Analysis}

Data collected from the autopsy studies using the appended proforma were entered on to the excel sheet and analysed using SPSS software. The results were tabulated in the form of tables.

\section{RESULTS}

In the present study series of 350 cases; occupants of motorcycles included 75.9\%, occupants of other vehicles like car $11.1 \%$, auto rickshaw $7.4 \%$, cyclists $2.6 \%$, bus $2 \%$ and lorry $1.1 \%$ were studied.

Among motorcycle occupants, $73.9 \%$ were riders and $26.1 \%$ were pillion riders. The car occupants involved in this series were 39 in number, with 23 front seat occupants other than drivers (59\%), 15 drivers (38.5\%) and one back seat occupant (2.6\%). Among the auto rickshaw occupants $65.4 \%$ were passengers and $34.6 \%$ were drivers.

Among the 350 cases studied 306 cases were males and 44 cases were females which gives a sex incidence of $87.4 \%$ males and $12.6 \%$ females.

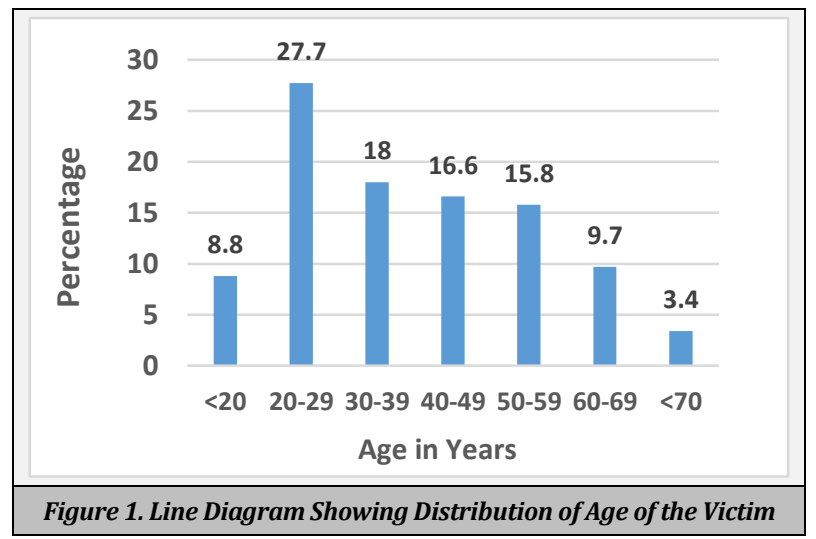


In this study series the maximum fatalities were observed in motorcyclists. Most commonly affected age group among the motorcyclists was 20 to 29 years (32.8\%), followed by 30 to 39 years $(18.4 \%)$ and least incidence was less than 15 years $(0.75 \%)$.

With regard to the occupation of the victim, those with business were most commonly affected $27.1 \%$, followed by students $22 \%$, jobless $20.6 \%$, manual labourers $6.9 \%$, government servants $2.3 \%$ and drivers $1.7 \%$.

Among the victims, no history of natural disease was given by $84.6 \%$, but $9.4 \%$ had either diabetes mellitus or hypertension and $6 \%$ had both diabetes (DM) and hypertension (HTN).

In this study series; it is observed that the highest number of cases took place in state highways (43.7\%) followed by national highways (30.9\%) and remaining $25.4 \%$ in other roads.

The highest incidence of accidents occurred between 6 PM to 9 PM (28\%) followed by 3 PM to 6 PM (23.1\%) and the lowest incidence was between $3 \mathrm{AM}$ to $6 \mathrm{AM}$ (1.4\%); and $68.2 \%$ of accidents were between 3 PM to 12 midnight and 51.1\% was between 3 PM to 9 PM.

According to the history given by the police regarding the nature of impact on the victims' vehicle; front on collision was the most common mode of impact (41.4\%) followed by hit from side.

Most of the victims survived for less than 24 hours $(63.4 \%)$ within the hospital. Whereas $14.6 \%$ died on the spot or on their way to the hospital; $7.7 \%$ survived for 1 to 3 days, $8.3 \%$ for 3 to 7 days and $2.6 \%$ survived above 7 days and died within 10 days and $2.3 \%$ survived up to 14 days and survival of more than 14 days were seen in $1.1 \%$ cases.

Blood samples were collected from 17 cases (13 motorcyclists, 2 car drivers and 2 auto rickshaw drivers) at autopsy for the estimation of ethyl alcohol in cases where stomach contents had sour smell. All the chemical results came positive for ethyl alcohol with range of $31.5 \mathrm{mg} \%$ to $164 \mathrm{mg} \%$.

\begin{tabular}{|c|c|c|c|c|c|c|c|}
\hline \multirow{2}{*}{$\begin{array}{c}\text { Type } \\
\text { of } \\
\text { Offending } \\
\text { Vehicle }\end{array}$} & \multirow[b]{2}{*}{$\begin{array}{l}\text { Motor } \\
\text { Cycle }\end{array}$} & \multicolumn{5}{|c|}{ Type of Vehicle } & \multirow[b]{2}{*}{ Total } \\
\hline & & Cycle & Car & Lorry & Bus & $\begin{array}{c}\text { Auto } \\
\text { Rickshaw }\end{array}$ & \\
\hline None & 32 & 1 & 0 & 0 & 0 & 2 & 35 \\
\hline Motorcycle & 64 & 2 & 0 & 0 & 0 & 1 & 67 \\
\hline Cycle & 13 & 0 & 2 & 0 & 0 & 1 & 16 \\
\hline Car & 69 & 1 & 11 & 0 & 3 & 12 & 96 \\
\hline Lorry & 34 & 2 & 18 & 3 & 0 & 4 & 61 \\
\hline Bus & 44 & 2 & 8 & 1 & 3 & 3 & 61 \\
\hline $\begin{array}{c}\text { Auto } \\
\text { rickshaw }\end{array}$ & 4 & 1 & 0 & 0 & 1 & 0 & 6 \\
\hline $\begin{array}{l}\text { Unknown } \\
\text { vehicle }\end{array}$ & 5 & 0 & 0 & 0 & 0 & 3 & 8 \\
\hline Total & 265 & 9 & 39 & 4 & 7 & 26 & 350 \\
\hline & & Table & vpe & Offer & $n g$ & icle & \\
\hline
\end{tabular}

Regarding safety measures used by the victims; among the 197 motorcyclists only $3.5 \%$ used helmets and among the pillion riders $2.9 \%$ wore it. In case of car occupants overall $13.3 \%$ of the drivers used seat belts. None on the front and back seats used it.

The most common type of injury seen in all forms of occupants were abrasions (100\%), followed by contusions and then lacerations. Among abrasions the most common area involved were face and neck, followed by chest and right upper limbs. Contusions were most commonly seen on scalp followed by face, neck and chest. Lacerations too had the greatest occurrence over the scalp, followed by face and chest.

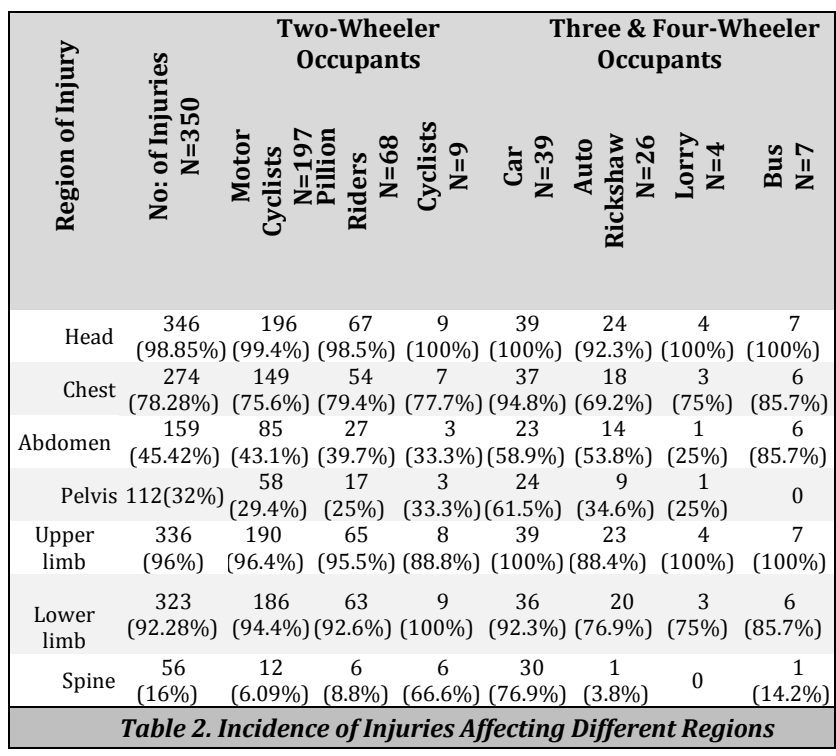

Among the motorcyclists with head injury (196 cases); skull fractures were seen in $77.5 \%$ of cases. Intracranial haemorrhages, brain injury or raised intracranial tension were seen in $85.2 \%$ cases. Among the pillion riders, $98.5 \%$ had head injury of which $88 \%$ had skull fracture and $98.5 \%$ had intracranial involvement. All the cyclists had head injury, with skull fracture and intracranial involvement in $88 \%$ each. Car occupants showed skull fracture in $64 \%$ with intracranial involvement in any form in $76.9 \%$. In car occupants all the drivers had skull fractures, in front seat occupants, skull fractures were seen in $28 \%$. In auto rickshaw occupants, all drivers $(100 \%)$ and $88 \%$ of passengers had head injury with $66.6 \%$ each having skull fractures, intracranial haemorrhages and brain injury. Among the occupants of lorry $100 \%$ had head injury with $75 \%$ each having skull fracture and brain haemorrhages. All the bus occupants had head injuries, but skull fractures seen only in $57.1 \%$ and $85.7 \%$ were with intracranial involvement. Intra cranial involvement without fracture skull was seen in few cases in all groups except in cyclists and auto rickshaw occupants. Highest percentage was seen in bus occupant (28.5\%).

Chest injuries were seen in $75.6 \%$ of motorcyclists. Among them rib fracture and lung injury were seen in $44.2 \%$ each. Sternal fracture was seen in $8 \%$, injuries to the heart in $3 \%$, and injuries to the aorta in $1.3 \%$. Among the pillion riders $22.2 \%$ had rib fractures, sternal fracture in $9.2 \%$, and lung injury in $1.8 \%$. Chest injuries were seen in $77.5 \%$ of cyclists with rib fracture in 57\% and lung injury in $14.2 \%$. All the drivers of car had chest injuries with a lesser frequency among other car occupants. Rib fractures were seen in $67.5 \%$ of drivers, $37.8 \%$ had sternal fractures and $59.4 \%$ had lung injuries and injuries to the heart in $5.4 \% .66 .6 \%$ of the lorry occupants had rib fractures and lung injuries; whereas in the bus occupants $50 \%$ each had rib fracture and lung injury.

Injury to the heart was seen in one bus occupant (16.6\%). Chest injuries were seen in $50 \%$ of auto rickshaw occupants and rib fracture in $50 \%$, lung injury in $22.2 \%$ and sternal fracture

in

$11.1 \%$ 


\begin{tabular}{|c|c|c|c|c|c|c|c|c|}
\hline \multirow[b]{2}{*}{$\begin{array}{l}\text { Type of } \\
\text { Occupant }\end{array}$} & \multirow{2}{*}{$\begin{array}{l}\text { Total No. } \\
\text { Of } \\
\text { Cases }\end{array}$} & \multirow[b]{2}{*}{$\begin{array}{c}\text { No. of } \\
\text { Abdominal } \\
\text { Injuries }\end{array}$} & \multicolumn{6}{|c|}{ Distribution of Abdominal Injuries } \\
\hline & & & Liver & Spleen & Kidney & Stomach & Intestine & $\begin{array}{l}\text { Urinary } \\
\text { Bladder }\end{array}$ \\
\hline Motor cyclists & 197 & $85(43.1 \%)$ & $7(8.2 \%)$ & $4(4.7 \%)$ & $2(2.3 \%)$ & - & $3(3.5 \%)$ & $3(3.5 \%)$ \\
\hline Pillion rider & 68 & $27(39.7 \%)$ & $1(3.7 \%)$ & $1(3.7 \%)$ & - & - & - & - \\
\hline Cyclists & 9 & $3(33.3 \%)$ & - & - & $1(33.3 \%)$ & - & - & - \\
\hline Car & 39 & $23(59 \%)$ & $7(30.4 \%)$ & $2(8.6 \%)$ & $4(17.3 \%)$ & $1(4.3 \%)$ & & - \\
\hline Lorry & 4 & $1(25 \%)$ & - & - & - & - & - & - \\
\hline Bus & 7 & $6(85.7 \%)$ & $1(16.6 \%)$ & - & - & - & - & - \\
\hline Auto rickshaw & 26 & $14(53.8 \%)$ & - & - & - & - & - & - \\
\hline Total & 350 & $159(45.4 \%)$ & $16(10 \%)$ & $7(4.4 \%)$ & $7(4.4 \%)$ & $1(0.6 \%)$ & $3(1.8 \%)$ & $3(1.8 \%)$ \\
\hline \multicolumn{9}{|c|}{ Table 3. Distribution of Abdominal Injuries } \\
\hline
\end{tabular}

The incidence of pelvic injury was $29.4 \%$ in motorcyclists. It was either fractures of pubic symphysis (12\%), Ilium $(1.7 \%)$, pubis $(5.1 \%)$ and sacroiliac joint $(12 \%)$. Among the pillion riders, only one case showed bony pelvic injury in the form of fracture separation of sacroiliac joint. Similarly, only one case of the cyclist had fracture separation of the pubic symphysis. Among the car occupants, only drivers showed deeper pelvic injury with $8 \%$ each of fracture pubic symphysis and sacroiliac joint. None of the lorry or bus occupants had pelvic injury. Among the auto rickshaw occupants, $11.1 \%$ each had fracture pubis and fracture sacroiliac joint and $22.2 \%$ showed fracture separation of pubic symphysis.

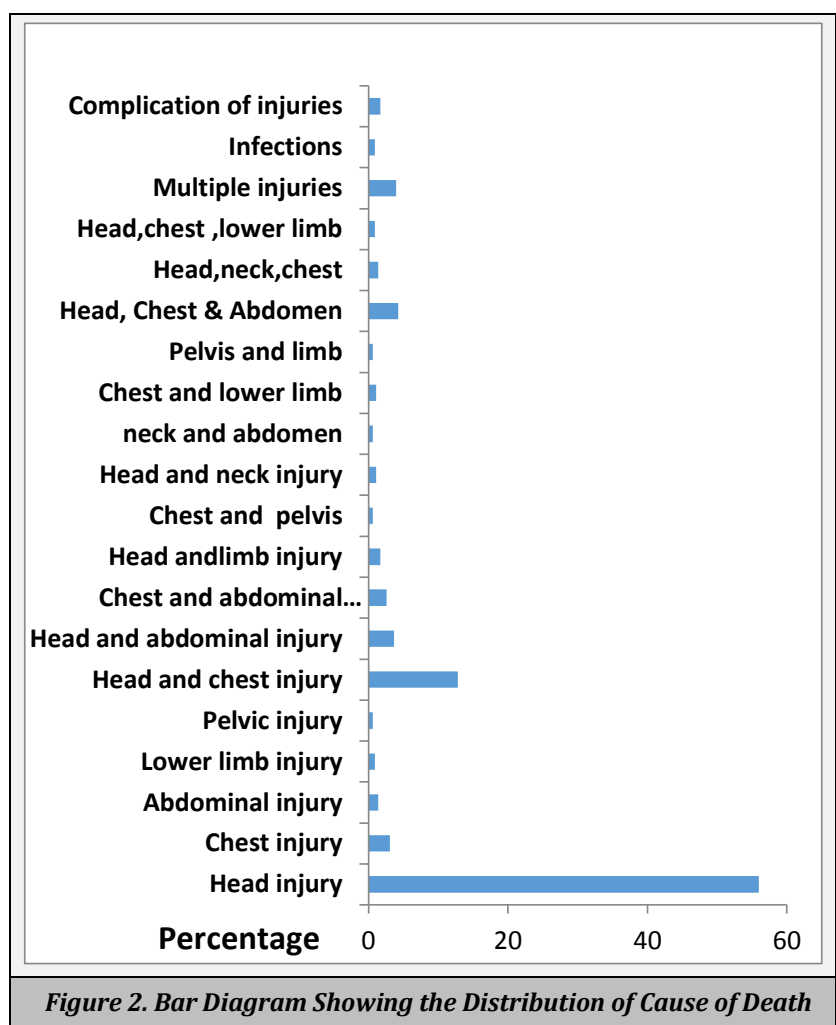

Injuries to the upper limb were seen in $96.4 \%$ and $95.5 \%$ of motorcyclists and pillion riders respectively. It was seen as of fractures of humerus $2.6 \%$, radius $1.5 \%$, ulna $2.1 \%$ in motorcyclists and in pillion riders in $1.5 \%$ had shown fracture of humerus, ulna and radius fracture in $3 \%$ and clavicle fracture in $1.5 \%$. Among the car occupants, $2.5 \%$ each had fracture humerus and radius respectively; both being front seat occupants. Fracture of upper limb was not seen in cyclists, lorry and auto rickshaw occupants. Regarding bus occupants only on case had upper limb fracture (14.2\%) in the form of fracture humerus.
Injuries to lower limb were seen in $94.4 \%$ motorcyclists, $92.6 \%$ of pillion riders and all cyclists. In motorcyclists, fractures were seen in femur $10.7 \%$, tibia $3.2 \%$ and fibula $1.65 \%$. Among pillion riders with lower limb injuries, fracture femur was seen in $9.5 \%$ and fracture tibia in $4.7 \%$. Even though $100 \%$ of cyclists had lower limb injuries only $11.1 \%$ had bony injury in the form of fracture femur. Among the car occupants, $92.3 \%$ had injuries to lower limb with $11.1 \%$ fracture femur, $2.7 \%$ each of fracture tibia and patella.

Among the 350 victims studied, 56 had external injuries in relation to the vertebral column, of which greater frequency was seen among drivers and front seat occupants of car $53.5 \%$ each. Among the motorcyclists, external injury in the back of trunk was seen in $6 \%$ cases of which $66.6 \%$ had cervical vertebral fracture, $33.3 \%$ thoracic vertebral fracture and $8.3 \%$ had lumbar vertebral fracture; with spinal cord injury seen among $83.3 \%$ of them. In the case of pillion riders, $8.8 \%$ had external injuries around the spine of which $66.6 \%$ and $33.3 \%$ had fracture of cervical and thoracic vertebra respectively. Regarding the car occupants, $10 \%$ of total cases with external injury had cervical vertebral fracture.

\section{DISCUSSION}

In developed countries accidents are shown to be numerous as in underdeveloped countries. It is increasing rapidly as a cause of death in absolute numbers and in term of proportions.

Sevitt's (1966) on 250 cases; $50 \%$ were pedestrians. $^{2}$ Among the occupants were motorcyclists $15.2 \%$, pillion riders $1.2 \%$, cyclists $7.2 \%$ drivers $12 \%$ and passengers $12.8 \%$. In Dr. Panduranga Shenoy's study on 100 cases; pedestrians were $53 \%$. Occupants of vehicle other than motorcyclists were $30 \%$, motorcyclists were $3 \%$, drivers $2 \%$ and others $4 \%{ }^{3}$ In Dr. Geetha (2001) on 250 cases, motorcyclists were $22 \%$, of cyclists $8 \%$, drivers were $4.8 \%$, other passengers were $15.6 \%{ }^{4}$ The present study was found not in agreement with both these studies as the aim of the study was different. In the present study, the male female ratio was $87.4: 12$. 6. Dr. Shenoy's series $(1979)^{3}$ it was $88: 12$, Geetha (2001) ${ }^{4}$ series it was 83.1:16.9. Increased male proportion can be easily explained by their relatively high rates of mobility as compared to females.

In the present study the maximum incidence was in the age group 20-29 yrs. (27.7\%); followed by the age group 30 39 yrs. (18\%) and then $40-49$ yrs. (16.6\%). Around $62.3 \%$ of road traffic accidents were found between the age group 20 to $49 \mathrm{yrs}$. This finding is very much comparable with Geetha. 0 were the maximum incidence was in $20-29$ yrs. (19.2\%), followed by $30-39$ yrs. (18\%) and 40-49 yrs. (16.8\%) and 
around $54 \%$ of the accidents were between 20 to 49 years. ${ }^{4}$ Whereas Shenoy's series it was $30 \%, 14 \%$ and $11 \%$ respectively, along with an overall incidence of $55 \% .^{3}$ The reason for the high frequency among youngsters can be explained by their increased mobility and over enthusiasm in driving and rashness in using vehicles as compared to aged individuals. In the present study also among the 350 subjects 98.85\% cases had head injury of any form, and $77.7 \%$ had shown fracture skull and $85.5 \%$ had intracranial involvement. This was found almost in agreement with Dr. Geetha's study, where the cases of head injury were $84.4 \%$, fracture skull in $75.4 \%$ and $97.6 \%$ had intracranial involvement. 4

Internal injuries to chest were seen in 274 cases. Among the study group $78.28 \%$ cases had chest injuries; of which $44.1 \%$ had rib fractures and $39.4 \%$ had lung injury, $2.9 \%$ with heart injuries and $0.7 \%$ had injury to aorta. Findings were not in agreement with Dr. Geetha's study where chest injuries were seen in $30.8 \%$ cases. Among them fracture ribs seen in $96.1 \%$, lung injuries $20.8 \%$, heart injuries $6.5 \%$ and injury to the aorta in $1.29 \% .^{4}$ Many a times we may see at autopsy were individuals who have survived a road accident in the past dies out of no reason. On opening the aorta, we can see faint, horizontally placed, linear scars on the intimal surface distal to the left subclavian artery origin. These represent the healed incomplete lacerations of the aorta. ${ }^{5}$. It was believed that the aortic injury occurred due to deceleration forces, now it has been understood that it is the chest compression which is the predominant aetiology behind it. ${ }^{6}$ Although seat belts reduce the incidence of aortic injuries, it is not the same with side impact crashes. ${ }^{7}$ Due to highly mobile chest wall in young cases there can be rupture of bronchus without any rib fracturing ${ }^{8}$. Partial avulsion of the lung from the bronchial tree, contusion and even crushing of lobes is also common, which may lead on to extensive haemorrhage. ${ }^{9}$

One or the other forms of abdominal injury were seen in 159 cases (45.4\%). Among the study group of 350 cases $45.4 \%$ had abdominal injuries. The highest incidence was with bus occupant $(85.7 \%)$ but with least internal injuries. Overall fatal abdominal injuries were sustained to car occupants $59 \%$, of which $30.4 \%$ had liver injuries and $17.3 \%$ were with renal injuries. Least fatal abdominal injuries were noted in motorcyclists with $8.2 \%$ liver injuries, splenic injuries $4.7 \%$, renal injuries $2 \%$ and intestinal $3.5 \%$ and urinary bladder injuries $3.5 \%$. It was also noted that abdominal injuries were the cause of death only in $1.4 \%$ of cases. In many cases it forms only a secondary cause of death. The most common organ affected in abdominal injury is liver (10\%). This finding is in agreement with Dr. Geetha's study; proving liver to be the most common organ affected by abdominal trauma followed by spleen and kidney $4.4 \%$ each. 4

Among the 350 cases studied 112 cases had shown pelvic injuries. Among them, fracture separation of pubic symphysis was seen in $10.7 \%$ cases and pelvic fractures in $8.2 \%$ cases. This finding is not in agreement with Dr. Geetha's study where with fracture pelvis was seen in 6.8\%.4 Highest number of fractures in pelvic region was seen with motorcyclists followed by car occupants. Pelvic fracture in motorcyclists can be explained by high velocity and front impact. According to Mason, in car occupants the sudden deceleration force pushes the front seat occupant on to the dashboard when the force can get conducted to the pelvis via knee. ${ }^{10}$ In the present study that $96 \%$ (336 cases) of the total cases sustained upper limb injuries. And in motor cyclists it was $96.4 \%$ and $95.5 \%$ in pillion riders. $2.6 \%$ cases had fracture humerus also; whereas in Dr. Geetha's study it was $5.4 \%$. Only $2.5 \%$ cases of front seat occupant sustained fracture of humerus and were not in agreement with Dr. Geetha's study which says $33.3 \%$ case of drivers sustained humerus fracture. ${ }^{4}$ Bernard knight; says gripping force in case of drivers makes them prone for upper limb fracture. ${ }^{11}$

Injuries to the lower limbs were seen in 323 cases (92.3\%). Which included motorcyclists $(94.4 \%)$ and car occupants $(92.3 \%)$ on top of the list. In $11.1 \%$ cases of car occupants had shown fracture femur. This can be explained by the upward conducted force from lower limb following sudden deceleration after impact. According to Dr. Geetha's study $10.3 \%$ of front seat occupants of car had fracture of femur and the finding is almost similar to the present study. ${ }^{4}$ Among 10.7\% motorcyclists had fracture femur which can be explained. According to Bernard Knight; the injuries of lower limbs of motorcyclists are often occurring either due to primary impact with other vehicle or when their legs gets trapped by the motorcycle frame. ${ }^{11}$

Cervical vertebrae fracture was seen in $10 \%$ of car occupants, and all of them had associated spinal cord injury. 56 cases with injuries around vertebral column cervical fracture was seen in $28.5 \%$ and $30.3 \%$ had spinal cord injury. According to Dr. Geetha's study $38.8 \%$ of the total cases had cervical fracture among those with external injuries around spinal region. ${ }^{4}$

Head injury was the most common cause of death in motorcyclists accounting for $62.26 \%$ of cases. Whereas in Sevitt's series it was $80 \%{ }^{2}$. In Dr. Geetha study it was $96.3 \%{ }^{4}$ The second most common cause of death in motorcyclists is the combination of head and chest injuries (11.3\%), but in Sevitt's series and Geetha study it was chest injury alone as the second most common cause of death in motor cyclists (25.4\%).

\section{CONCLUSIONS}

The present study aimed to cover the pattern of injuries sustained to various strata of occupants based on the vehicles that they were travelling in. The manner of causation of the injuries was discussed in detail. Maximum fatalities were in the age group of 20 - 29 years and $62.3 \%$ belonged to $20-49$ years of age group. Regarding the period of survival $63.4 \%$ of victims died within $24 \mathrm{hrs}$. of accident. Among the 350 cases, 346 of them (98.5\%) had head injury. Strict laws should be brought against drunken driving, rash driving and driving without helmets, seat belts, and using mobile phones while driving. Violation of traffic rules must be viewed seriously. 


\section{REFERENCES}

[1] Spitz WU, Fisher RS. Medicolegal investigation of death. $2^{\text {nd }}$ edn. Springfield IL: Charles. C. Thomas 1978:377-404.

[2] Sevitt S. Fatal road accidents. Injuries, complications, and causes of death in 250 subjects. Br J Surg 1968;55(7):481505.

[3] Shenoy P. Investigation into traffic accidents. Thesis submitted to University of Kerala for MD (Forensic medicine) 1976.

[4] Geetha 0. Pattern of injuries in victims of road traffic accidents. Thesis submitted to University of Kerala for MD (Forensic medicine) 2001.

[5] Shkrum MJ, Ramsay DA. Forensic pathology of trauma. $1^{\text {st }}$ edn. USA: Humana Press Springer 2007:288-9.
[6] Wyatt JP, Tim S, Norfolk G, et al. Oxford handbook of forensic medicine. $1^{\text {st }}$ edn. New York: Oxford University Press 2011:155-6.

[7] Lawrence PF. Essentials of general surgery. $4^{\text {th }}$ edn. Philadelphia: Lippincott Williams and Wilkins 2006:1945.

[8] Vij K. Textbook of forensic medicine and toxicology principles and practice. $5^{\text {th }}$ edn. Elsevier Publications 2011:293-5.

[9] Burke MP. Forensic medical investigation of motor vehicle incidents. 1st edn. USA: CRC Press Taylor and Francis Group 2010:61-72.

[10] Mason JK. The pathology of trauma. $1^{\text {st }}$ edn. London: Edward Arnold 1972:1-43. Bernard K. Forensic pathology. 1st edn. London: Edward Arnold 1990:252-72. 